\title{
Parenting Styles and Gender as Predictors of Social Intelligence among Adolescents in Idoma Land
}

Joyce M. Terwase

Department of Psychology, Benue State University, Makurdi; terwasejm@gmail.com

Reuben Lubem Ibaishwa

Department of Psychology, Benue State University, Makurdi

Joy Enemari

Department of Psychology, Benue State University, Makurdi

\section{Doi:10.5901/mjss.2016.v7n1s1p181}

\section{Abstract}

\begin{abstract}
The research investigated parenting style and gender as predictors of social intelligence among adolescents in Idoma Land. The study adopted the ex post facto research design. Questionnaires on parenting style and social intelligence were used for data collection. A total of two hundred and ninety four (294) participants made up of 151 males and 143 females participated in the study. Their ages ranged from 12-17 years. Findings showed that only permissive parenting style positively and significantly predicts social intelligence $(\beta=118 ; p<.05)$ while authoritarian parenting style $(\beta=.113 ; p>.05)$; authoritative $(\beta=.102 ; p>$ $.05)$ and gender $(\beta=-.064 ; p>.05)$ did not predict social intelligence. The result also reveal that parenting style and gender jointly and significantly predict social intelligence on $F$ value of 3.585 which is significant at 0.01 alpha level. It is recommended that NGOs, private firms, stakeholders within the field and related government agencies should take into consideration the impact of parenting styles on social intelligence in order to organize seminars, workshops, talk shows and public lectures for parents and the masses as well as to create awareness, and the need for counselors, to educate parents about social intelligence. Parents on the other hand should adopt suitable parenting styles that will boast their children's level of social intelligence.
\end{abstract}

Keywords: Parenting Styles, Gender, Social Intelligence and Adolescents

\section{Introduction}

It has become a truism that "no two individuals are exactly alike". Individuals are born distinct from each other and are unique in their own way. The fact of being distinct and unique from one another has sometimes become a big factor why problems in dealing and relating to other people arise (Lacanlale, 2013). But as a social being, man cannot refrain from socializing with others in his social environment. He needs to relate and interact with others interpersonally for his survival, growth and development. That "No man is an island," shows man's relationship to other people as very important. He needs to make adjustments in relating to others in various situations to sustain and maintain his relationship. His interpersonal relationship with others affects his relationship towards himself. His self-concept, selfesteem, and self-efficacy are being influenced by his relationship to other people (Lacanlale, 2013).

Man is a social being, and in his everyday living, he comes to meet and interact with different types of people with different personalities. Because of individual differences, man comes to experience misunderstandings, conflicts, quarrels and frustrations in life if he cannot manage and direct his social relationships. The problem in meeting individual differences has now become prevalent in every group and society. Compromising differences, resolving conflicts, and enhancing personal and social relations have now become a challenge to every individual. Because of these, man needs to become adaptive and flexible in dealing with others to develop healthy and smooth relationships. He needs an understanding on how to operate and handle various situations, and he should have an idea about his social environment where he is interacting. To respond to these needs, man's social intelligence is deemed to be important (Lacanlale, 2013).

Social intelligence is man's ability to understand happenings around him and to react to those happenings in a 
personal and social manner. In other words, social intelligence is the ability to act in different social situations, to discover other people's feelings and interests, to organize groups and negotiate solutions, to establish personal relationships with others, to express one's feelings to others to interact and participate with others in various events, to recover from embarrassing situations with the least possible losses, to recognize one's errors and failures, to adapt quickly to any medium one is placed in, and to persuade others of one's personal view (Darwish, 2003). Social intelligence was coined by Thorndike (1920) and he refers to it as an individual's ability to have an understanding of people and manage them, and engage in positive social interactions.

Social intelligence as a construct has attracted many researchers. These researchers, however, many have been able to study social intelligence in relation to certain variables which are perceived as predictors of social intelligence. The effect of these variables on social intelligence has been studied such as creativity (Singh, 2007), home environment and socio-economic status (Kaur \& Kalaramna, 2004), wisdom, values and interpersonal personality traits (Vyrost \& Kyselova, 2006), age (Chesnokova, 2005), gender and parents' occupation (Gnanadevan, 2007) among other variables. Majority of these studies conducted on social intelligence were carried out in western societies with very few and that is if any conducted in Benue State. Due to this wide gap in the literature regarding foreign and home based peer review on social intelligence, the researcher examined gender and parenting styles as predictors of social intelligence among Idoma adolescents.

Parenting style is a psychological term representing acceptable methods that parents use in bringing up their children. Parents are an important aspect of a child's life and their behavior largely affects a child's development from the moment they are born. A child's parents and culture has an influence on parenting style that is used for the child's rearing. Parents may adopt their style of parenting from their own parents and may use some and not use others (Santrock, 2009). There are basically three types of parenting styles (Baumrind, 1971) and they include; Authoritative parenting style, Authoritarian parenting style and Permissive parenting style. Authoritative parenting style is the democratic style of parenting. Here, parents listen to their children, forgiving their children, teach the children acceptable behavior, develop a set of rules, and there is punishment if the child did not follow these set rules, but if adhered to, there is a positive reward. In authoritarian parenting, the parents are strict and have high expectations; there is little interaction between child and parent. Parents are rigid, demand much from the child and do not accept disobedient from the child. The child is to follow the strict rules set without question. On the other hand, permissive parenting style takes on the role of "friends" rather than parents. Parents that practice permissive parenting style do not have expectation from the child and give the child freedom to make his own decisions.

The empathy and social perception provided by social intelligence mean that individuals who experience authoritative parenting are high in social intelligence than individuals who experience authoritarian and permissive parenting styles. Such parenting styles like the authoritative enables children to develop high level of social intelligence thus, enabling children to develop and possess the capacity and ability to understand and manage their emotions and other people's emotions.

Another variable of interest in which the study examined its predictive power on social intelligence of adolescents is gender. Gender is the complex interrelationship between one's physical traits and one's internal sense of self as male, female, both or neither as well as one's outward presentations and behavior related to their perception. Gender is an important aspect that must be considered in social intelligence, in the sense that there is a significant difference between men and women on social intelligence (Money, 1995). Men are seen to have a rather poor way of interacting with the people around them due to their firm nature which makes him aggressive towards those that transgress rules. On the other hand, women accomplish tasks and still restrain aggression and anger toward others. Women are known to be nurturing, tender, sensitive, and intuitive in nature. Women are scared of things that men do not fear and often times, women are described as compassionate, charitable, agreeable, and kind. This gender division of social intelligence exists between adolescents in schools and homes.

It is a common knowledge that male and female don't have the same personality trait and their sexual roles differ. Thus, there is a possibility that social intelligence will however differ among male and female adolescents.

\section{Empirical Review}

\subsection{Parenting Styles and Social Intelligence}

Mohammadyari (2011) in his study examined the relationship between parental style and social intelligence among students of Payaeme Noor University in Iran. He used a descriptive design one and type of causal-comparison. He used a sample size of 75 students ( 28 men and 47 women) and used simple random sampling. The author collected data 
using Shaffer's Parental Styles Questionnaire (1991) and Social Intelligence Scale (SIS) developed by Chadda and Ganesan (2009). He found significant difference in the level of social intelligence of students based on the parenting styles that the students were reared with. One-way analysis of variance showed significant mean scores on social intelligence of children to differ based on parenting style and Tokay's test showed that there was a significant difference between social intelligence of students with authoritative parenting and neglectful parenting styles. Also the results showed that there was no significant difference between male and female students' in social intelligence.

Similarly, Abdollahi, Talib and Motalebi (2013) examined the association between perceived parenting styles and social intelligence in Iranian boy students. The sample size was 188 boy students (age from 16 to 19) were chosen by a multi-stage cluster sampling method. For gathering data, students filled out Parental bonding instrument (PBI), and assessing Social intelligence Scale. To analyze the data, Pearson correlation coefficient and multivariate regression analysis was used. The findings revealed there were positive associations between affectionate constraint parenting style, and optimal parenting style with high ability of social intelligence, and negative associations existed between affectionless control style and neglectful parenting style with high ability of social intelligence. The affectionate constraint parenting style was a powerful predictor of high ability of social intelligence, and neglectful parenting style was a plausible predictor of low ability of social intelligence in adolescents.

Finding from the review showed that studies have not being conducted in this part of the world (Benue State) that addresses the parenting styles and social intelligence among Idoma adolescents. Therefore, the following hypothesis was formulated

Hypothesis 1: Parenting styles will significantly and positively predict an social intelligence among Idoma adolescents.

\subsection{Gender and Social Intelligence}

Saxena and Jain (2013) conducted a study to know the social intelligence of male and female undergraduate students of science and arts subject streams studying in various degree colleges of Bhilai city, Chhattisgarh. A descriptive survey method was used. 60 male and 60 female undergraduate students were selected, for the sample by adopting stratified disproportionate random sampling technique. The data was collected by using Social Intelligence Scale (SIS) constructed and standardized by Chadda and Ganesan (2009). The data was analyzed using' independent t-test. The findings of gender analysis indicates that female student's posses more social intelligence than male students and analysis of stream indicates that arts students are having greater social intelligence than students of other streams.

Kumar (2014) studied the social intelligence of adolescents (boys and girls) by using social intelligence scale. Graduate students were randomly selected from the different colleges of Hazaribag district of Jharkhand. Sample of seventy (70) student's comprising 35 boys and 35 girls were selected. Social intelligence scale developed by Chadha and Ganeshan (2009) was used for the investigation. To accomplish the main objective, obtained data were analyzed to obtain the following i.e. mean, SD, t-ratio was used to have comparative analysis. And at the same time independent ttest was used to understand the gender difference. His result showed that Boys student have better Social intelligence in comparison to Girls student.

Based on the literature review, no study was found by the authors that address gender and social intelligence among Idoma adolescents in Benue State and in Nigeria in particular. It is based on this that the study formulated the following hypothesis

Hypothesis 2: Gender will significantly predict social intelligence among adolescents in Idoma land.

\section{Methodology}

\subsection{Research Design}

Ex-post-facto research design was adopted for this study and two (2) questionnaires were used to collect data among the participants used for the study. The independent variables in the study are parenting styles (which was investigated at 3 levels) and gender (was investigated at 2 levels) while the dependent variable which is social intelligence was investigated as a composite variable. Thus, a $3 \times 2$ factorial design was used.

\subsection{Participants}

The participants for the study were adolescents from the Idoma speaking areas of Benue state. A total number of 294 
participants whose ages ranged from 12-17 years of age, comprising 151 (51.4\%) male, and $143(48.6 \%)$ female were sampled out from Otukpo local government area in Idoma land.

\section{Measures}

\subsection{Parenting Style Scale}

The scale is a 20 item inventory developed by Baumrind (1971). The scale is scored on a 2 point ranging from Yes (1) to No (0) in each of the three categories of parenting styles. Authoritarian parenting style items: 1, 2, 3, 4, 5, 6, 7 .

Authoritative parenting style items includes: $8,9,10,11,12,13$. Permissive parenting style items includes: 14,15 , $16,17,18,19,20$. Baumrind (1971) reported the reliability alpha coefficient of .86 .

\subsection{Social Intelligence Scale}

The social intelligence scale was designed by Al-Ghoul (1993). It consists of two parts: a behavioral attitude test which consists of twenty-four items, and a verbal attitude test which consists of thirty items.

Behavioral Attitudes test: a test associated with acting wisely in social situations ability. It measures the extent to which students have skills and ability to act wisely according to social norms in public and social interaction situations.

Verbal Attitudes test: measures the ability of students to interact with others through social communication, effort to achieve satisfaction in social relationships and satisfaction of personal and social needs.

Each item contains three responses (always / sometimes / rarely), (Al-Qudra, 2007). The reliability coefficients calculated for the social intelligence scale was found to be .92 .

\subsection{Procedure of Research}

The participants were sampled from three (3) Universal Basic Education (UBE) secondary schools and Universal computer training institute Otukpo, where they were informed with the consent of the school authorities regarding the purpose of the study. The researchers administered the instruments to the participants in their schools. When consent was given, participants were briefed on the nature of the study and the task of responding to the instruments. They also received verbal instructions on how to respond to the items that made up the entire questionnaire. Participants were assured of confidentiality of their responses. With assistance from teachers of the schools, questionnaires were administered to participants as they were encountered. A total number of 300 questionnaires were administered in two (2) days and responded to, while a total number of 297 questionnaires were retrieved.

\subsection{Data Analysis}

The Multiple regression analysis was used to test the hypotheses formulated using the statistical package for social sciences (SPSS version 20.0.) was used to analyze the data.

\section{Results}

Table 1: Summary of multiple regression analysis showing parenting styles and gender as predictors of social intelligence

\begin{tabular}{|c|c|c|c|c|}
\hline Model & R & R Square & Adjusted R Square & Std. Error of the Estimate \\
\hline 1 & $.217^{\mathrm{a}}$ & .470 & .034 & 11.30505 \\
\hline
\end{tabular}

Table 2: Analysis of variance showing influence of parenting styles and gender on social intelligence

\begin{tabular}{|l|c|c|c|c|c|}
\hline Model & Sum of Squares & $\mathrm{df}$ & Mean Square & $\mathrm{F}$ & Sig. \\
\hline Regression & 1832.684 & 4 & 458.171 & 3.585 & $.007 \mathrm{~b}$ \\
1 Residual & 36935.397 & 289 & 127.804 & & \\
$\quad$ Total & 38768.082 & 293 & & & \\
\hline
\end{tabular}


Table 3: Regression of Parenting Styles and Gender on Social Intelligence

\begin{tabular}{lcccc}
\cline { 2 - 5 } Variables & Std. Error & Beta & $\mathrm{t}$ & $P$ \\
\cline { 2 - 6 } Authoritarian & .483 & .113 & 1.930 & .055 \\
Authoritative & .546 & .102 & 1.759 & .080 \\
Permissive & .416 & $.118^{*}$ & 1.992 & .047 \\
Gender & 1.336 & -.064 & -1.102 & .271 \\
Note: $*=P<.05 ; * * * P<.01$ & & & &
\end{tabular}

The results of regression analyses revealed that among the variables tested to examine their predictive power on social intelligence in the study, only permissive parenting style positively and significantly predict social intelligence $(\beta=118 ; p<$ $.05)$ while authoritarian parenting style $(\beta=.113 ; p>.05)$; authoritative $(\beta=.102 ; p>.05)$ and gender $(\beta=-.064 ; p>.05)$ did not predict social intelligence. This result indicated that permissive parenting style which is the type of parenting style that parents do not have any expectation of the child, they allow the child to make their own decisions and such parent see it as the ultimate goal in parenting, is the only factor in the study that positively predict social intelligence among Idoma adolescents .

The data in table 1 showed that the two independent variables, when taken together yielded a multiple regression coefficient (R) of .217, a multiple $R$ square $\left(R^{2}\right)$ of .047 . This means that .047 or 4.7 percent of the total variance in the social intelligence of Idoma adolescents can be explained by the combined influence of the two predictor variables (parenting styles (authoritarian, authoritative and permissive) and gender).

In addition, the data in Table 2 shows that the analysis of variance of simple regression analysis yielded an $\mathrm{F}$ value of 3.585 which is significant at 0.01 alpha level. This implies that parenting styles (authoritarian, authoritative and permissive) and gender jointly have a significant influence on social intelligence among Idoma adolescents.

\section{Discussion}

The result obtained showed that authoritarian parenting style was found not to significantly predict social intelligence of Idoma adolescents. This upholds that the way an adolescent interacts with people around them and get others to cooperate with them is not determined by being reared under an authoritarian parent whom have high expectation of their children and ensure adequate compliance from their children to their instructions and their set rules and regulation, neither is it determined by being reared under an authoritative parent who set high norms for children, monitor the norms they set, and also allow their children to develop autonomy, nor is it determined by differentiating between masculinity and femininity, that is being male or female does not predict the social intelligence of an individual as well. This is upheld by the study of Darling, Steinberg, and Brown (1993) whom in their study did not found authoritarian parenting to have a statistically significant impact on peer group affiliation. Similarly, this work also tallies with the research by Bednar and Fisher (2003) who indicated that adolescents with authoritarian parents would seek advice from their peers for social decision making, this implies that adolescents with authoritarian parents do not predict social intelligence.

It was also found that authoritative parenting style do not significantly predict social intelligence of Idoma adolescents. This upholds that being raised by a demanding and responsive parent cannot determine the way an adolescent interacts with people around them and get others to cooperate with them. This is contrary to the work of Darling, Steinberg, and Brown (1993) who examined the influence of specific parenting styles on peer group affiliation and found out that adolescents with authoritative parents were more often affiliated with well rounded crowds that oriented toward adult values and also involved more competent peer interactions. Also disagreeing with this finding is the works of Fuligni and Eccles (1993); Bednar and Fisher (2003) who found a significant influence of authoritarian parenting style on social intelligence.

It was also found that permissive parenting style is a significant predictor of social intelligence, this upholds that adolescents reared under permissive parents whom are nurturing and accepting, not demanding and are responsive to the child's needs and wishes tend to be socially intelligent and always have their way in social interactions and relationships. This is contrary to the work of Sarhaddi (2014) in his study to evaluate the relationship between parenting style and social intelligence of intelligent and normal students in high schools and found no significant relationship between permissive parenting (free mood method) and social intelligence.

Gender did not significantly predict social intelligence among adolescents in Idoma land. This upholds that one's sexual identity i.e. being male or female cannot determine the way an adolescent interact with people around them and get others to cooperate with them. This is upheld in a research by Al-Makahleh and Ziadat (2012) who carried out a study 
which identified the relationship between social intelligence and the behavioral characteristics of talented students in a middle school from the perspective of their teachers. The results indicated that there were no statistically significant differences in the average degree of response of the study sample due to the sex variable on both the social intelligence. In a similar study also, Mohammadyari (2011) found no significant difference between male and female students' on social intelligence.

The findings of the study equally revealed that parenting style and gender significantly and jointly predict social intelligence. This upholds that the type of child rearing pattern that an individual undergoes will determine how that individual is able to interact smoothly with others in social relationship and get them to cooperate with him. This finding is upheld by the work of Chopra and Nangru (2014), who examined family relationship of high school students in relation to their social intelligence and found that parental acceptance, has significant relationship with social intelligence likewise their gender. Similarly studies by Abdollahi, Talib and Motalebi (2013), Mohammadyari (2011), Latouf (2008), revealed the joint prediction of parenting styles and gender among adolescents.

\section{Conclusion}

Conclusively, the findings of this research revealed that authoritarian parenting, authoritative parenting, and gender do not significantly predict the social intelligence of Idoma adolescents. It was also revealed that permissive parenting have a significant influence on the social intelligence of Idoma adolescents. Furthermore, the findings also revealed that parenting styles and gender significantly and jointly predict the social intelligence of Idoma adolescents. Thus, these findings were empirically rooted giving evidences from previous research on the variables. However, it can be concluded that permissive parents can play a direct role in fostering their children's social intelligence.

\section{Recommendations}

Based on these findings, the following recommendations have been made;

i. It will be of great importance for NGOs, private firms, some stakeholders and government agencies to take into consideration the importance of parenting styles on social intelligence so as to organize seminar, workshops, talk shows and public lectures for parents and the masses as well to create awareness.

ii. There is a need for counsellors to educate parents during their counseling session on the importance of adopting a suitable parenting style which will determine their children's social intelligence in the future.

iii. Students need to learn how to manage misunderstandings, conflicts, quarrels and frustrations in life to enable them learn how to manage and direct their social relations compromising differences of the parenting style different individuals undergo, resolving conflicts, and enhancing personal and social relations so as to be flexible in dealing with others to develop healthy and smooth relationships in the society they live in.

\section{Suggestions for Further Studies}

Based on the results of this study, there's a need for other research to examine several questions. Some of these include the following:

i. Other researchers interested in expanding on this study should study the predictive power of other variables on the dependent variable (social intelligence) and subject the research to further study which is vast growing and resourceful to the body of knowledge.

ii. It will be of utmost importance that further research should involve other tribes, communities, work settings etc. as this will impact greatly to the society and not restrict the case study to a particular tribe.

iii. Also, very few have been done on the social intelligence of children and adults. This is another aspect to be looked at in the quest to suggest for further studies.

\section{References}

Abdollahi1, U., Talib, I., \& Motalebi, S. (2013). Perceived parenting styles and social Intelligence.

Ahmad, S., Bangash, H., \& Khan, S.A. (2009). Emotional intelligence and gender differences. Sarhad Journal of Agric, 25(1), 127-130.

Al-Ghoul, A.A. (1993). Self-efficacy and social intelligence and their relationship to some of the emotional factors of teachers, educators and non educators and their students' academic achievement. Unpublished Ph.D. thesis, submitted to the Faculty of Education, University of Assiut. 
Al Makahleh, A.A.A., \& Ziadat, H.A. (2012). Social intelligence and personal characteristics of talented secondary school students in King Abdullah II. Educational Research, 3(10), 785-798.

Baumrind, D. (1971). Current pattern of parental authority. Developmental Psychology, 4(2), 1-103.

Bednard, D.E., \& Fisher, T.D. (2003). Peer referencing in adolescent decision making as a function of perceived parenting style. Adolescence, 38, 607-621.

Chadda, N.K., \& Ganesan, U. (2009). Manual of social intelligence scale. Agra National Psychological cooperation.

Chesnokova, O. (2005), Cunning and social intelligence in children. Retrieved on 10/12/2013 from www.lancs.ac.uk

Chopra, R., \& Nangru, P. (2014). A study of family relationship in relation to emotional intelligence. International Indexed \& Refereed Research Journal, 5(42), 9-13.

Darling, N., \& Steinberg, L. (1993). Parenting style as context: A integrative model. Psychological Bulletin, 113(1), 487-496.

Darwish, Z.E. (2003). Human intelligence and life skills missing /Education, $1^{\text {st }}$ Edition. Bahrain.

Fuligni, A.J., \& Eccles, J.S., (1993). Perceived parent- child relationship and early adolescents orientation toward peers. Developmental psychology, 29 (4), $622-632$.

Gnanadevan, R. (2007). Social intelligence of higher secondary students in relation to their socio-economic status. Journal of Community Guidance and Research, 24(3), 340-346.

Goleman, D. (2006). Social intelligence: The new science of human relationships. New York: Bantam Books.

Jones, K., \& Day, J.D. (1997). Discrimination of two aspects of cognitive social intelligence from academic intelligence. Journal of educational psychology, 89(3), 486-497.

Kaur, H., \& Kalaramna, A. (2004). Study of interrelationship between home environment, social intelligence and socio-economic status among males and females. Journal of Human Ecology, 16(2), 137-140.

Kumar, V. (2014). Gender differences among adolescents on social intelligence. International Journal of Research, 1(1), 1-3.

Lacanlale, E.P. (2013) Development and validation of a social intelligence inventory international. Journal of Information and Education Technology, 3(2), 263- 267.

Latouf, N.D.S. (2008). Parenting styles affecting the behaviour of five year old.

Master thesis submitted in part fulfillment of the requirements for the degree of master of diaconiology (direction: play therapy) at the university of South Africa.

Mohammadyari, G. (2011). The relationship between parental style and emotional intelligence among students of Payame Noor University. Proceeding of the global summit on education (GSE2013)

Money, J. (1995). Hopkins pioneer in gender identity. Baltimore sun. Chicago, University of Chicago press.

Santrock, J.W. (2009). Introduction to child and adolescent practice in professional psychology.USA: Oxford University Press.

Sarhaddi, M. (2014). Evaluating the relationship between parenting styles and emotional intelligence; Dominant parenting style associated with high social capabilities and positive social compatibility. FRAMT France Ltd.

Saxena, S., \& Jain, R.K. (2013). Social intelligence of undergraduate students in relation to their gender and subject stream. IOSR Journal of Research \& Method in Education (IOSR-JRME), 1(1) 1-4

Singh, S. (2007). Emotional intelligence, social intelligence, adjustment and personality differentials of adolescents with high \& low creativity. Unpublished Ph.D. Thesis.

Thorndike, E.L. (1920). Intelligence and its use. Harper's Magazine, 140, 227-235.

Vyrost, J., \& Kyselova, M. (2006). Personality correlates of social intelligence. Studia Psychologica, 48(3), $207-212$. 